\title{
AQUEOUS SOL-GEL DERIVED NANOCOMPOSITE COATING MATERIALS
}

\author{
H.K. SCHMIDT', E. ARPAC ${ }^{2}$, H. SCHIRRA', S. SEPEUR', G. JONSCHKER' \\ 'Institut fuer Neue Materialien gem. GmbH, Im Stadtwald, Bldg. 43 A, D-66 123 \\ Saarbruecken, Germany, schmidt@inm-gmbh,de \\ ${ }^{2}$ Akdeniz Üniversitesi, Fen Edebiyat Fakilltesi, PK 510, 07200 Antalya, Turkey
}

\begin{abstract}
Sol-gel reactions, in general, have to take place in organic solvents in order to control the hydrolysis and condensation reaction. This leads to drawbacks in applications, since the organic solvent vapor concentration has to be controlled for example in coating applications for environmental, health or security reasons. For this reason, a reaction route has been developed to produce coating precursors stable against water as solvent. To achieve this, conventional electrostatically stabilized sols obtained either by hydrolysis and condensation or commercially available sols (c.g. $\mathrm{SiO}_{2}$ sols) have been surface-modified to reduce the particle-to-particle interaction and electrosterically stabilized precursors compatible to water have been obtained. By use of alkoxy silanes as surface modifiers, water-dispersable nanoparticulate liquid coating systems have been prepared, for example, with boelumite, $\mathrm{SiO}_{2}$ or $\mathrm{TiO}_{2}$ as nanoparticles to be crosslinked after coating thermally by inorganic condensation and organic condensation or polymerization reactions. Thus, aqueous sol-gel coating systems have been prepared with EtOH contents below $5 \%$. In the paper, the basic reaction as well as material properties will be discussed.
\end{abstract}

\section{INTRODUCTION}

Sol-gel science has become an interesting area in research, development and up-coming industrial application during the last 50 years. As already pointed out by Zarzycki [1], the development of inorganic materials still has not shown its large break-through in industry with a few exceptions like large-scale coatings (for example Schott's IROX ${ }^{\oplus}$ glass or $\mathrm{Al}_{2} \mathrm{O}_{3} / \mathrm{SiO}_{2} / \mathrm{B}_{2} \mathrm{O}_{3}$ fibers, Merck's coated mica pigments or some very specific ceramic powders). Other minor applications are under development. According to Zarzycki's opinion, the field of hybrid sol-gel materials shows the largest application potential, and from the scientific point of view, a great number of scientists have started to take care of this field since 1975. This can be seen very clearly by following, for example, the number of presentations in the MRS annual meetings, especially in the "Better Ceramics Through Chemistry" symposium, with a special issue on hybrid organic-inorganic materials in 1996 [2]. Meanwhile, many industrial applications based on hybrid materials have been reported, especially in connection with transparent hard coatings $[3,4,5,6]$. Other systems related to sol-gel techniques are polysiloxane-based hard coatings, such as the General Electric system for automotive polycarbonate headlights. Interesting industrial applications are anti-adhesive coatings [7] in the carpet fabrication, spin-on glasses [8], hybrid binders for zink-containing anti-corrosive paints or sol-gel glass fiber binders $[9,10,11]$.

The classical approach of sol-gel science is to use alkoxide precursors in order to have a soluble source for the inorganic component. For this reason, at the beginning, sol-gel science 
was mainly devoted to alkoxides of various metals and of silicon. Silicon was a very interesting component since hybrid precursors have been available leading to the first investigations of hybrid materials, and new names like Ormosils, Ormocers, Ceramers or Polycerams have been created. One of the common features of these precursors is their solubility in organic solvents, and this led to a situation that the utmost part of all research carried out in the sol-gel field is carried out with organic solvents, mainly in alkohols. Early work in the sol-gel field still implemented water-based sols such as LUDOX ${ }^{\text {a }}$, and first investigations carried out on $\mathrm{SiO}_{2}$ gels in numerous cases were based on the aqueous process. LUDOX ${ }^{\circledast}$ is stabilized by ionic additives in order to create repulsion forces on top of the $\mathrm{SiO}_{2}$ nanoparticles. This, however, never led to a water-based sol-gel science except in industrial processes for the production of nixed powders, for example, from $\mathrm{SiO}_{2}$ and $\mathrm{Al}_{2} \mathrm{O}_{3}$ for catalytic carriers. But this never was considered to be a classical sol-gel process. Especially in the area of hybrid materials where the solubility of hybrid precursors such as alkyl alkoxy silanes is only high in organic solvents, water never played a role. For this reasons, investigations on water-based processing routes are the real exceptions. Most of the efforts have been made by industrial companies to use colloidal silica as a cheap additive to different matrices [12]. E. Takeuchi et al describe a process where silanes were dispersed in an aqueous dispersion of a polymer obtained by emulsion polymerization [13]. T. Shimomura et al. describe the reaction of aqueous colloidal silica with organofunctionalized silanes with high concentration of phosphoric acid. Coatings with high breakdown voltage and resistance to boiling water are described [14]. R. Frye describes coatings fabricated from colloidal silica and water-dispersible resins having alkoxy silane groupings [15]. Frye is also describing a system where aryl and alkyl hydroxy silanes are hydrolyzed in the presence of aqueous colloidal silica, but in order to get reasonable solutions, isobutoxy alcohol has to be used. Ganbark et al. [16] describe a similar system where silanes are hydrolyzed in the presence of aqueous colloidal silica, but for further processing also use organic solvents like glycols, glycol ethers, alcohols or others. Kuryama et al. [17] describe a system based on methacryloxy silanes hydrolyzed with water-soluble acrylates and acrylic acid as a water-based silane containing coating system. Chu et al. [18] mixed colloidal silica with epoxy silanes. They observed a decrease of silica $\mathrm{OH}$ groups with increasing content of epoxy silane, but they also used high amounts of ethanol in order to obtain appropriate homogeneity for processing (over $30 \%$ in addition to the methanol produced by the hydrolysis of the epoxy silane).

The state of the art shows that it might be rather difficult to end up with very low organic solvent contents in liquid hybrid systems. The most important drawback is the reactivity of the silanes which is difficult to be stopped in the presence of excess water.

However, on the other side, for industrial application to develop water-based systems it seems to be an extremely attractive issue due to the problems of environmental protection, health hazards, security and, of course, production costs due to expensive equipment for the removal or organic solvents, for example, in a coating plant. For this reason, investigations have been carried out in order to develop a generalizable route for waterbome hybrid sol-gel processing.

\section{GENERAL ASPECTS}

Sols stabilized in aqueous solutions are easily to be obtained by electric charge (or electrostatic) stabilization as known from aqueous colloidal silica or aqueous boehmite sols. Boehmite sols, for example, can be stabilized by the addition of acidic acid or propionic acid, as shown in fig. 1. 


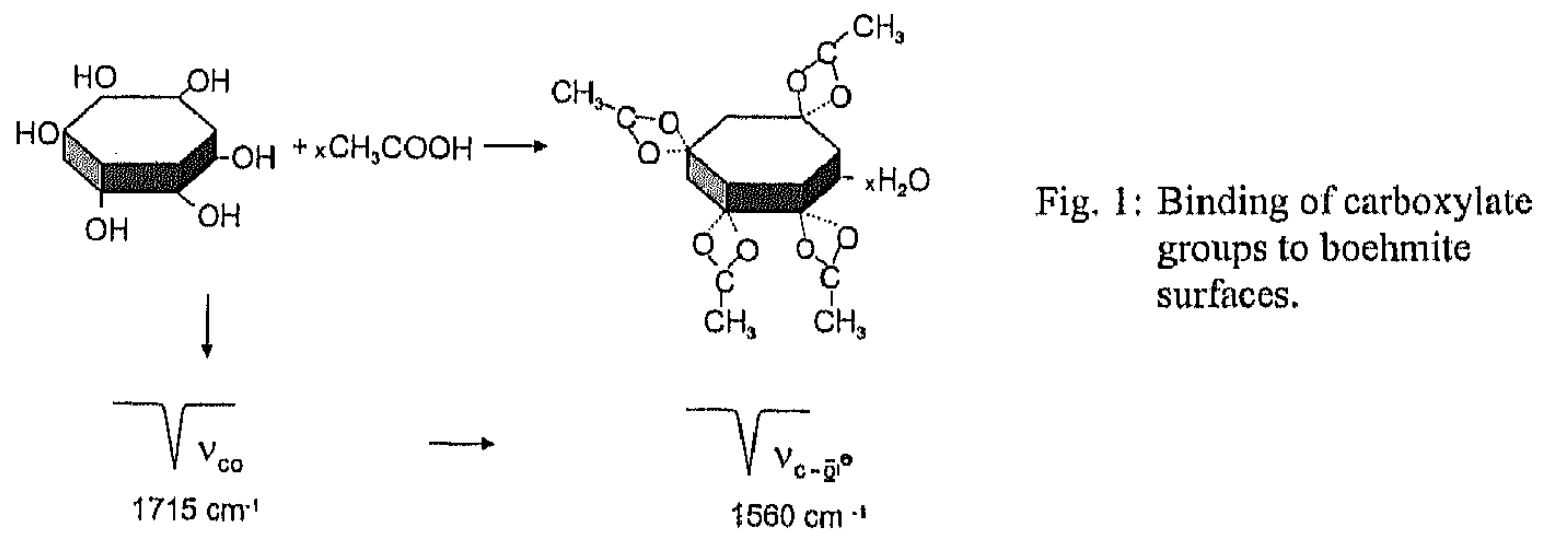

The reaction can be observed by IR spectroscopy with a shift of the frequency of the free carbonyl group to the carboxylate frequency [19]. Acetic acid stabilized to boehmite meanwhile is a commercial product from Condea Chenical Company. This type of stabilized boehmite can easily be dispersed in water and forms stable sols due to the electrostatic stabilization which is due to the reversible dissorption of the acetic acid and the formation of electric charges on the boehmite particle surface. From many investigations in literature [20], it is known that the hydrolysis, for example, of $\gamma$-glycidyloxypropyl trimethoxysilane is very slow with water and reaches an equilibrium state with partially unhydrolyzed silane depending on concentration, alcohol and water content. These prehydrolyzed single component systems can be used for making coatings, but the mechanical properties of such coatings are rather poor. Moreover, the trimethoxysilane produces methanol, which for many applications is not very suitable due to its toxic properties. But it should be possible to combine both principles, the use of alkoxysilanes slowly reacting with water and the use of aqueous sols to develop water-based nanocomposite systems based on this route. For this reason, it has to be investigated whether the electrostatic stabilization can be substituted by an "hydrophilic" electrosteric stabilization which is used at the same time for preventing or slowing down the hydrolysis and condensation reaction. The aim of this paper is to show that material developments are possible using this approach.

\section{EXPERIMENTAL}

3-(glycidyloxy)propyl triethoxysilane (glyeo) and 3-(glycidyloxy)propyl trimethoxysilane (glymo) were hydrolyzed with various concentrations of 0.1 normal $\mathrm{HCl}, 1.0,1.5$ and 2 mole water per mole hydrolyzable OR grouping at room temperature (RT) for $2-10 \mathrm{~h}$. The produced alcohol (from the hydrolysis and condensation reaction of the silane) was removed by vacuum distillation at a temperature of maximum $40{ }^{\circ} \mathrm{C}$ until the portion of the residual alcohol in the sol is maximum 10 vol.-\%. After addition of an aqueous silica sol (30 weight-\% $\mathrm{SiO}_{2}$. stabilized in an acidic aqueous media, Bayer Levasil ${ }^{\Phi} 200$ S) the sol was stirred for $5-24$ lirs at RT, As catalyzer for the organic polyaddition and inorganic polycondensation $2 \mathrm{wt} .-0 \%$ (relatively to glyeo) of the aminosilane $\mathrm{N}$-(2-aminoethyl-3-aminopropyl)-trimethoxysilane (diamo) was added. This mixture was stirred for minimum $1 \mathrm{~h}$ to prepare a sol-gel based and water-borne coating material. 
The synthesis of the hydrophobic coating material was carried out by the stoichiometric (OR: $\mathrm{H}_{2} \mathrm{O}=1: 1$ ) cohydrolysis of glyeo with 2,5 mole- $\%$ tridecafluoro- $1,1,2,2$,-tetrahydrooctyl1-triethoxysilane (FS) under acidic catalysis ( 0.1 normal aqueous $\mathrm{HCl}$ ). After 24 hrs stirring the produced alcohol was removed by vacuum supported distillation. The residue was mixed with an acidic stabilized aqueous silica sol (see above) and stirred for $4 \mathrm{~h}$ at RT. After this time 2,5 mol-\% N-(2-aminoethyl-3-aminopropyl)-trimethoxysilane (diamo) was added and stirred for minimum $1 \mathrm{~h}$.

Polycarbonate substrates have been coated after a corona treatment by a spin-on process dried at room temperature for $30 \mathrm{~min}$ and cured at $130^{\circ} \mathrm{C}$ for $4 \mathrm{hrs}$. The abrasion resistance was tested with a taber abrader test using aluminum oxide-filled rubber wheels (CS10F) with 1,000 cycles (the standard tests for plastic surfaces is 100 cycles). The load was $500 \mathrm{~g}$. In an analogous manner, $\mathrm{CR} 39$ and $\mathrm{Al}$ was coated. $\mathrm{CR} 39$ was cured at $90^{\circ} \mathrm{C}$ only. Adhesion tests were performed by the cross cut test followed by the tape test. Weathering tests were carried out with a $100 \%$ relative humidity at $40^{\circ} \mathrm{C}$. The coated metal substrates were corrosion tested in a closed salt spray chamber $\left(\mathrm{T}=35^{\circ} \mathrm{C}\right)$ with a relative humidity of $100 \%$ and a salt concentration of $5 \mathrm{wt} .-\% \mathrm{NaCl}$ in water. The particle size was detected by photon correlation spectroscopy. ${ }^{29} \mathrm{Si}$-NMR liquid spectra have been carried out with a multi core spectroscope (frequency $39 \mathrm{MHz}$, pulsing angle $20-26 \mu \mathrm{s}$ ). With the same device ${ }^{13} \mathrm{C}-\mathrm{NMR}$ liquid spectra (frequency $50 \mathrm{MHz}$, pulsing angle $9.2 \mu \mathrm{s}$ ) were carried out. ${ }^{13} \mathrm{C}-\mathrm{MAS}-\mathrm{NMR}$ spectra were recorded with a Bruker solid state $200 \mathrm{MHz}$ NMR spectrometer (frequency $50 \mathrm{MHz}$, pulsing angle HPDEC $50^{\circ}$ ).

Molecular mass distribution analysis was carried out by gel permeation chromatography (GPC). A combination of 2 themostatic controlled $\left(T=40^{\circ} \mathrm{C}\right)$ polystyrol filled columns $(100$ and $1000 \AA$ ) were used with the elution solvent THF. The detection was carried out by the online measurement of the elutional refractive index.

$\zeta$-potential measurements have been carried out with the Malvern zeta sizer 4 . The $\zeta$-potential was determined by a titration with $\mathrm{NaOH}$, using the electrophoretic mobility $\mu$ to calculate the $\zeta$-potential.

\section{RESULTS}

For deciding whether glyeo is suitable for the preparation of epoxy hybrids as it has been shown with glymo [18] the hydrolysis behavior of the glyeo was compared to that of glymo. ${ }^{29} \mathrm{Si}-\mathrm{NMR}$ investigations were carried out with respect to the hydrolysis and first step condensation rates. In fig. 2 and 3 the NMR spectra are shown. In both cases (glymo and glyeo) the degree of condensation increases with an increasing stoichiometry (ratio of $\mathrm{H}_{2} \mathrm{O}: \mathrm{OR}$ ) of the hydrolysis reaction. This behaviour is more distinct in the glyeo prehydrolysate where the threefold crosslinked species $\left(\mathrm{T}_{3}\right)$ appear first in the 2-fold stoichiometric prehydrolysis. The main difference between glymo and glyeo hydrolysis and condensation behaviour is the fact, that all not hydrolyzed monomers $\left(\mathbb{T}_{0}^{0}\right)$ have disappeared even in the 1.5 fold stoichiometric hydrolysis whereas in all glymo spectra $\mathrm{T}_{0}{ }^{0}$ species can be detected. As it can be seen overall from the NMR spectra, the methoxysilane and the ethoxysilane show a similar condensation behavior after $2 \mathrm{~h}$. 

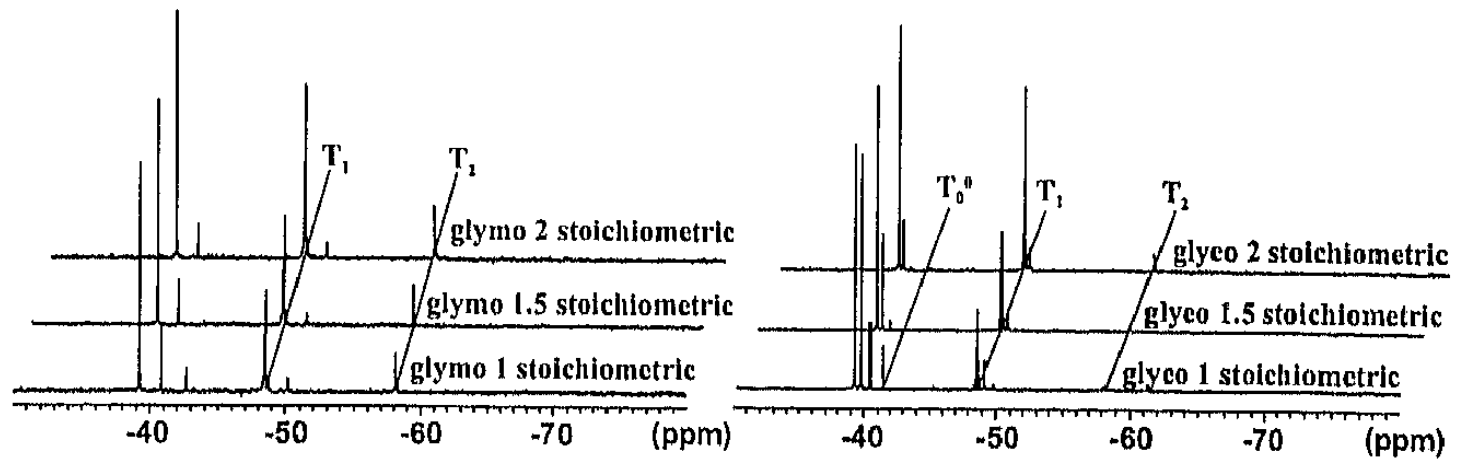

Fig. 2 and 3: ${ }^{29} \mathrm{Si}-\mathrm{NMR}$ spectra of the hydrolysis and condensation reaction of glymo and glyeo with 0.1 normal hydrochloric acid for $2 \mathrm{~h}$ at RT. Per mol hydrolyzable Si-OR grouping $1,1.5$ and 2 mole water ( $\mathrm{HCl}$ ) were used.

The results indicate that ethoxysilane can be used in a similar way for the preparation of condensates as the methoxysilane. Therefore, these systems contain EtOH from the hydrolysis of the silane, which sums up to EtOH : silane $\approx 3: 1$ (molar ratio); the EtOH acts as a compatibilizer leading to a homogeneous solution soon after the beginning of the hydrolysis reaction. In order to produce organic solvent-free systems, the hydrolyzed silane was upconcentrated by removal of EtOH ( $<10$ vol.\%) under vacuum, and ${ }^{20} \mathrm{Si}-\mathrm{NMR}$ spectra were produced from the concentrate. No precipitation or cloudiness appears during this step.

These ${ }^{29} \mathrm{Si}$ NNMR spectra look very similar to those without EtOH removal after a reaction time of 24 hrs. That means, due to the removal of $\mathrm{EtOH}$, the equilibrium is shifted strongly to the product side. As a standard procedure, 5-7 hrs hydrolysis including the EtOH removal at the end were defined.

In the next step, an aqueous dispersion of acid-stabilized silica sol (Bayer $200 \mathrm{~S}$ ) with a solid content of $30 \%$ by weight was added. Again ${ }^{29} \mathrm{Si}-\mathrm{NMR}$ analysis was carried out after $30 \mathrm{~min}$. In opposition to the systems not treated with a silica sol after a total reaction time of $7 \mathrm{hrs}$ and 30 min, no $T_{0}{ }^{2}$ peaks and only traces of $T_{0}{ }^{3}$ peaks can be observed. After 3 more hrs, no more hydrolyzed silane monomers are present (fig. 4), but the ${ }^{13} \mathrm{C}-\mathrm{NMR}$ spectrum shows that even after 21 hrs, the epoxy ring is still intact. All investigations show that homogeneous transparent liquids can be prepared.

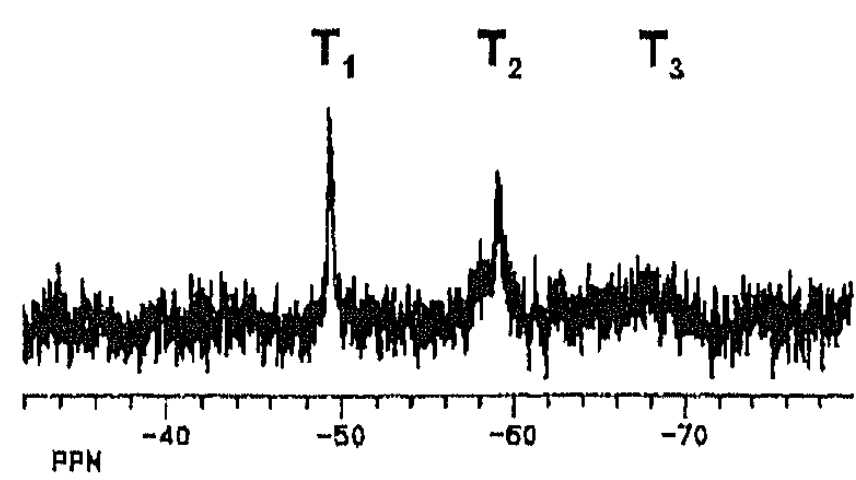

Fig. 4: ${ }^{29} \mathrm{Si}-\mathrm{NMR}$ of the hydrolyzed epoxy silane after the vacuum supported removal of the alcohol and after addition of aqueous colloidal $\mathrm{SiO}_{2}$.

In fig. 5 a high resolution TEM micrograph of a film made from the suspension is shown.

The micrograph shows the same particle size distribution as the colloidal silica of Bayer $200 \mathrm{~S}$, with particle sizes up to $12-15 \mathrm{~nm}$. Due to the small particle size, the systems appear completely transparent. 


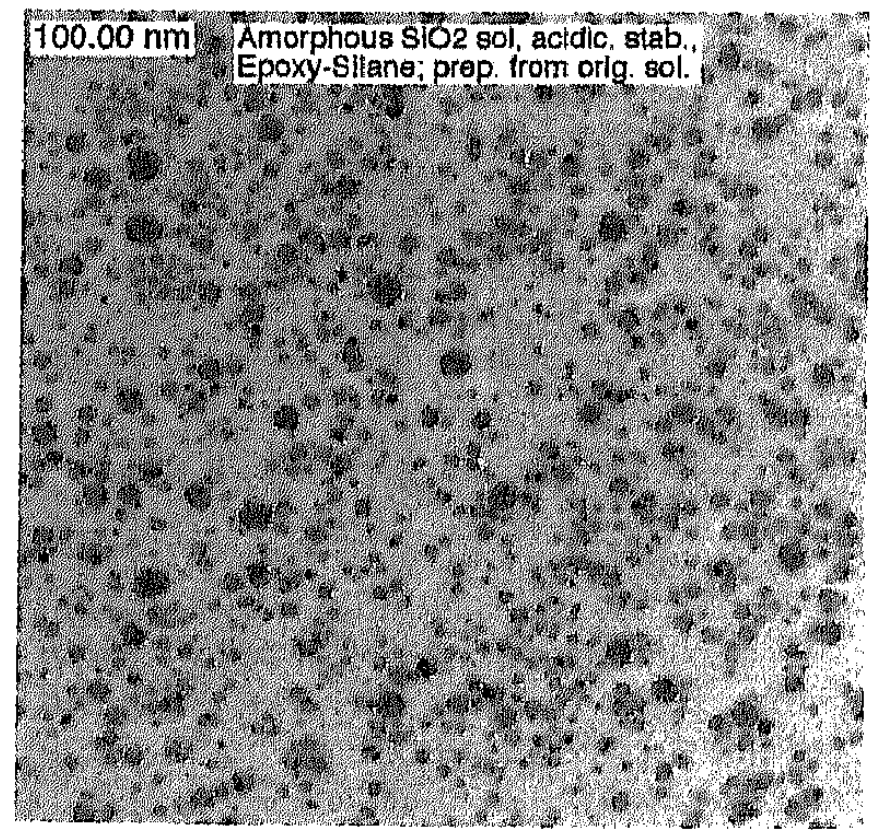

Fig. 5: High-resolution TEM micrograph of a colloidal silica-modified epoxysilane sol.

The particle size was also determined by photon correlation spectroscopy and is shown in table I, which correlates fairly to the HRTEM data. It is shown that the particle size remains constant within 10 days storage time.

Table I: Particle size and viscosity of $\mathrm{SiO}_{2}$-sol/glyeo systems as a function of storage time (at RT).

\begin{tabular}{|c|c|c|c|c|c|c|c|}
\hline $\begin{array}{l}\text { Storage } \\
\text { time [days] }\end{array}$ & 1 & 2 & 3 & 6 & 7 & 8 & 10 \\
\hline $\begin{array}{l}\text { viscosity } \\
{[\mathrm{mPas}]}\end{array}$ & 21 & 35 & 39 & 51 & 54 & 61 & 71 \\
\hline $\begin{array}{l}\text { average } \\
\text { particle size } \\
{[\mathrm{nm}]}\end{array}$ & 12.3 & 12.3 & 12.9 & 13.4 & 12.7 & 10.4 & 12.2 \\
\hline
\end{tabular}

During the 10 days storage time, the viscosity increases slowly from 21 to $71 \mathrm{mPas}$, which can be attributed to a further condensation of the silane. The solvent content of the system was determined to be $40 \mathrm{wt} . \mathrm{\%}$ water and about $4 \%$ alcohol (ethanol). This means that the system represents a high solid system mainly based on water as solvent.

In order to evaluate the structure of the liquid nanocomposite system, GPC and NMR investigations have been carried out with glymo systems prepared under corresponding experimental conditions to estimate the molecular weight distribution of the system. Gel permeation chromatographic experiments compared with ${ }^{20} \mathrm{Si}-\mathrm{NMR}$ data (fig. 6 and 7) show that the degree of condensation in this type of epoxysilanes is rather low [21]. 


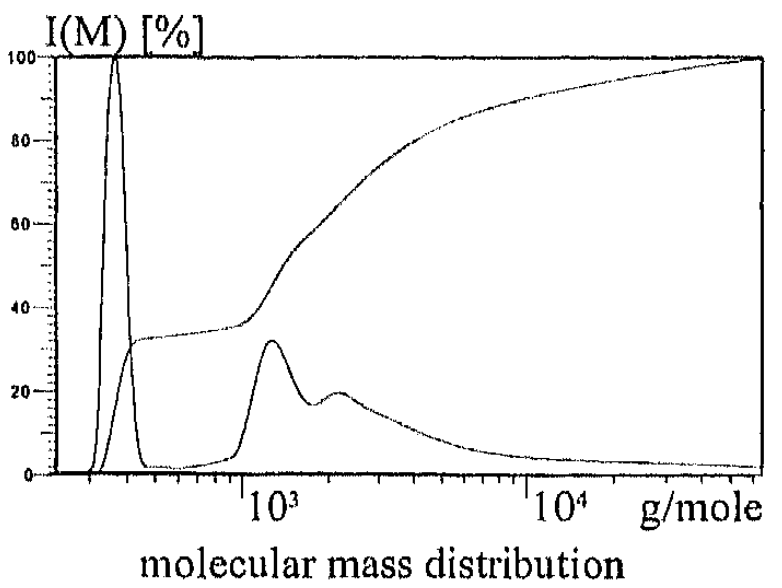

Fig. 6: Gel permeation chromatographic investigation of the stoichiometrically prehydrolyzed glymo ( $5 \mathrm{~h}, \mathrm{RT}, 0.1$ normal hydrochloric acid);

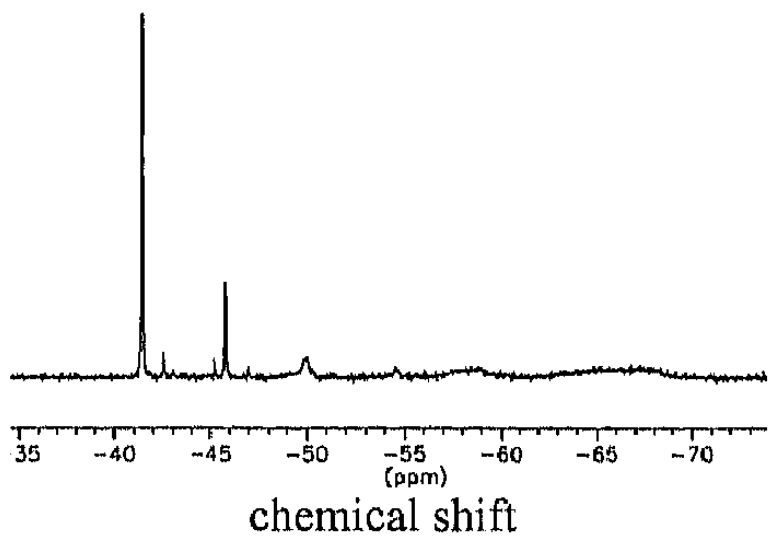

Fig. 7: ${ }^{29}$ Si-NMR spectroscopic investigation of the stoichiometrically prehydrolyzed glymo ( $5 \mathrm{~h}, \mathrm{RT}, 0.1$ normal hydrochloric acid); $\mathrm{T}_{0} \approx 41 \mathrm{ppm}$; $\mathrm{T}_{1} \approx 46 \mathrm{ppm} ; \mathrm{T}_{2} \approx 50 \mathrm{ppm} ; \mathrm{T}_{3} \approx 54 \mathrm{ppm}$.

In fig. 6 the gel permeation chromatography of a prehydrolyzed glymo system is shown. The peak at about 200 molecular mass units (a) is caused by hydrolyzed and not hydrolyzed monomers of glymo, the peaks at $10^{3}$ molecular mass units (b) and higher are mainly due to oligomeric structures up to about 10 monomer units. On the average, the maximum of the units per macromolecule is in the range of about 10 silanes. This is in good correlation with the ${ }^{29} \mathrm{Si}-$ NMR also taken after 5 hrs, from which after quantitative evaluation an average degree of condensation of $50 \%$ was estimated (fig. 7).

Based on these findings and especially due to the fact that silica sol reduces the number of $\mathrm{T}_{0}$ species of the epoxysilane considerably, a model has been proposed for this type of waterbased colloidal silica particle containing epoxides, which is shown in fig. 8. This model, however, suggests the change in the surface properties of the $\mathrm{SiO}_{2}$.

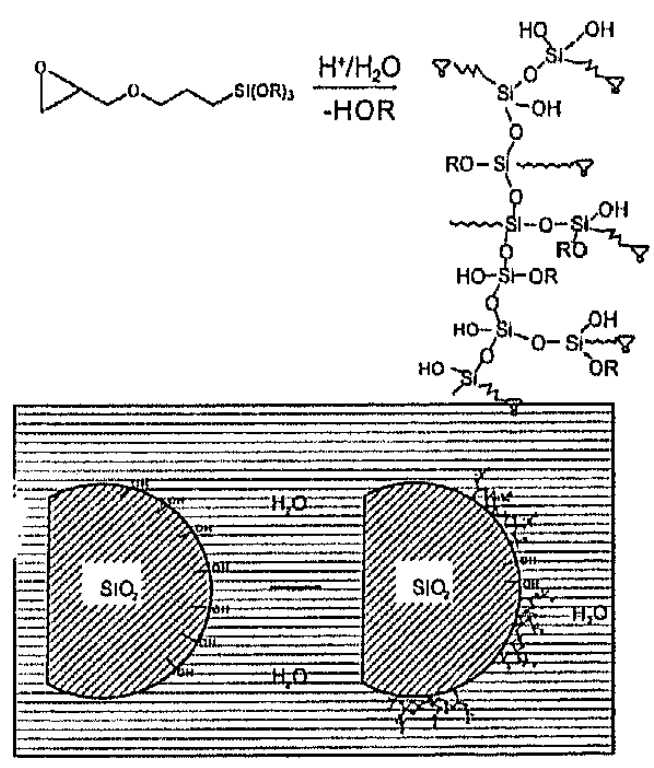

Fig. 8: Model of the formation of water-stable particulate epoxysilane sols. 
In order to enhance the condensation, an aminosilane (N-(2-aminoethyl-3-aminopropyl)-trimethoxy silane, diamo) was added, as described in the experimental. The concentration of the aminosilane was in the range of about $2 \mathrm{wt} .-\%$ only with respect to the reaction mixture since this was considered to be sufficient for catalytic purposes. The silane was added after the removal of the ethanol and after addition of the aqueous sol. In fig. 9 the ${ }^{29} \mathrm{Si}-\mathrm{NMR}$ spectrum is shown, and the concentration of the $T_{1}$ species is considerably lower than without the aminosilane.

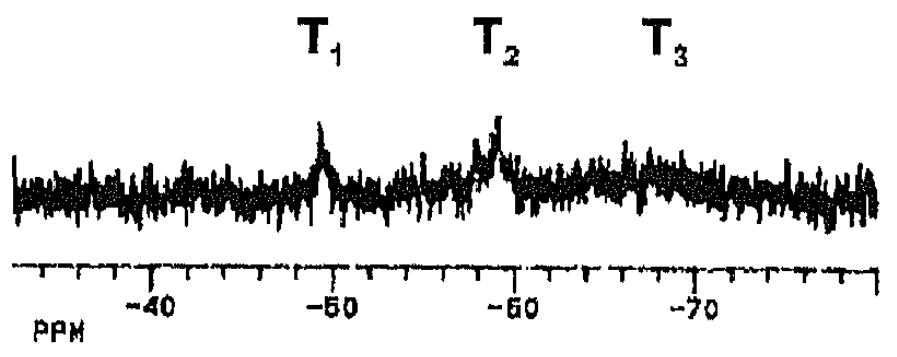

Fig. 9: ${ }^{29}$ Si-NMR of the system prehydrolyzed glyeo/SiO $\mathrm{S}_{2}$ after addition of the aminosilane $(\mathrm{N}$ (2-aminoethyl-3-aminopropyl)trimethoxy silane, diano).

This can be attributed to the well known effect of the amino groupings as condensation catalysts. As shown by ${ }^{13} \mathrm{C}-\mathrm{NMR}$, even after seven days the epoxy ring is still present in almost its starting concentration. However, these systems show slightly larger particle sizes and a stronger increase of the viscosity than the amino group-free systems, as shown in table II.

Table II: Particle size and viscosity of $\mathrm{SiO}_{2}$-sol/glyeo/diamo systems as a function of storage time (at RT).

\begin{tabular}{|c|c|c|c|c|c|}
\hline $\begin{array}{l}\text { storage time } \\
\text { [days] }\end{array}$ & 1 & 2 & 3 & 4 & 5 \\
\hline $\begin{array}{l}\text { viscosity } \\
{[\mathrm{mPas}]}\end{array}$ & 27.5 & 39.3 & 60.6 & 93.7 & 136.5 \\
\hline $\begin{array}{l}\text { average par- } \\
\text { ticle size }[\mathrm{nm}]\end{array}$ & 19.0 & 15.4 & 13.7 & 15.9 & 15.1 \\
\hline
\end{tabular}

The faster increase is attributed to the catalytic effect of the amino groupings. The particle size is a little bit larger than in the diamo-free systems. This effect may be attributed to the binding of larger condensates to the particle surface, but the molecular weight distribution in the diamo case could not be investigated so far.

Referring to the model shown in fig. 8, the question arises about the stabilization mechanisms of the water-based colloid-containing condensates. As it may be conducted from the model, the particles and the condensates covering the particle still are able to absorb ions or electric charges and to display a $\zeta$-potential. $\zeta$-potential measurements have been carried out as shown in fig. 10 .

The $\zeta$-potential investigations show a clear difference between silica particles before and after prehydrolysis and condensation reaction with a drastical change of the isoelectric point from 2.8 (unmodified $\mathrm{SiO}_{2}$ ) to 6.4 (modified particles). This means, that by the described process an electrosterically stabilized sol-gel nanocomposite system has been developed, where the main solvent is water. Due to the electrosteric stabilization documented by the existence of a $\zeta$ potential between $-35 \mathrm{mV}$ and $+25 \mathrm{mV}$ depending on $\mathrm{pH}$ the compability with water as well 
as a remarkable stabilization is obtained. This leads to a generalisable route for the synthesis of water-borne nanocomposite materials.

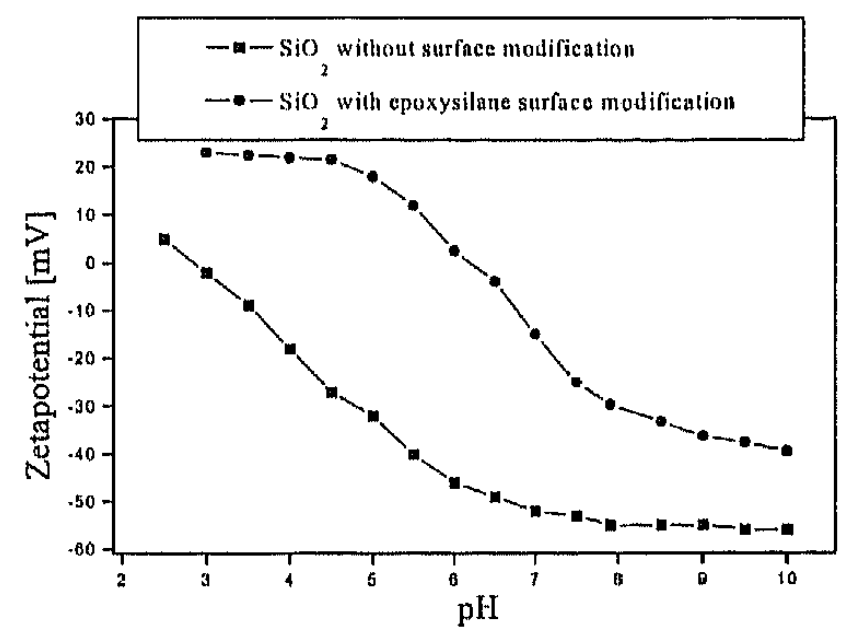

Fig. 10: Zetapotential measurements of unmodified silica particles from Bayer Levasi ${ }^{\oplus} 200 \mathrm{~S}$ in comparison with epoxysilane surface modified silica particles as product from the prehydrolysis and condensation reaction mentioned above

First results with other colloidal particles such as titania or alumina show that the basic principle can be employed to other colloidal systems and other silane precursors [22]. In fig. 11 , the flow diagram of the complete process is shown.

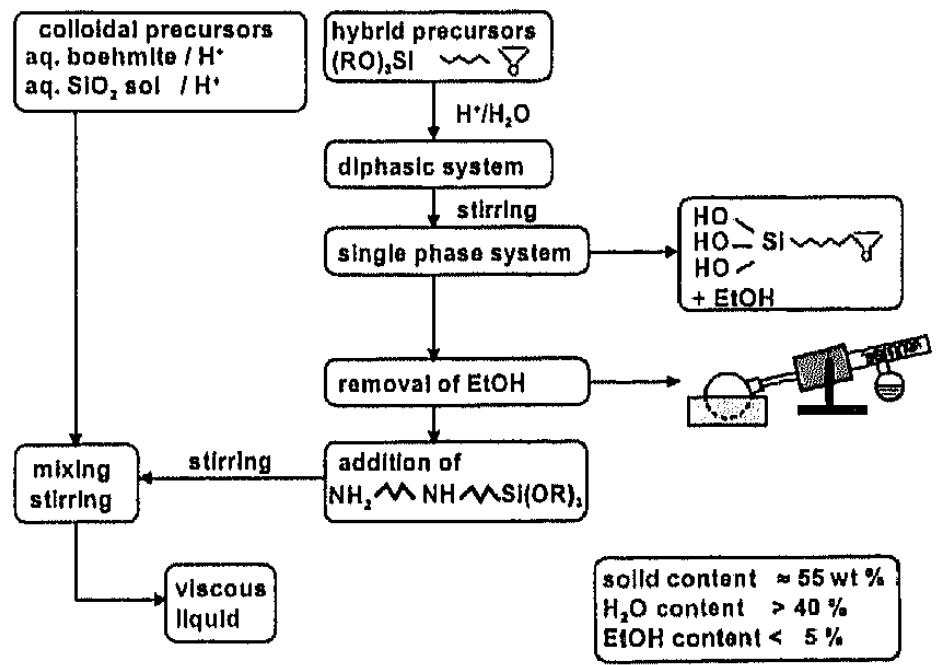

Fig. 11: Scheme of the preparation process for water-based glyeo/diamo/ $\mathrm{SiO}_{2}$ nanocomposite systems.

Another interesting question was how far these systems can be modified with typical hydrophobic systems such as silanes containing perfluorinated side chains. For this reason, as in detail described in the experimental, glyeo was collydrolyzed with 2.5 mole- $\%$ of tridecafluoro1,1,2,2,-tetrahydrooctyl-1-triethoxysilane (FS). The cohydrolysis was followed by ${ }^{29} \mathrm{Si-NMR}$ spectroscopy (fig. 12). As it can be seen from the NMR spectrum, the precursor molecule FS has disappeared after less than two hrs, resulting in a 1-phased highly homogeneous solution. This means, that the FS can be homogeneously incorporated into the condensate. In analogy to the FS-free systems, aqueous $\mathrm{SiO}_{2}$ sols can be added after the EtOH removal.

Homogeneous coating systems could be prepared using this approach between 0.5 mole- $\%$ up to 10 mole- $\%$ of FS. However, the viscosity after preparation increased from $40 \mathrm{mPa}(0.5 \%)$ to $340 \mathrm{mPas}$, which is probably due to a higher degree of condensation in this system, but no simple explanation could be found for this phenomenon. However, it is rather surprising that aqueous systems could be prepared with fluorosilane contents up to 10 mole $\%$. This may be 
partly attributed to the increase of the critical micell concentration through colloidal $\mathrm{SiO}_{2}$ as it was already shown by Krämer [23] in a similar system by the addition of boehmite sols.

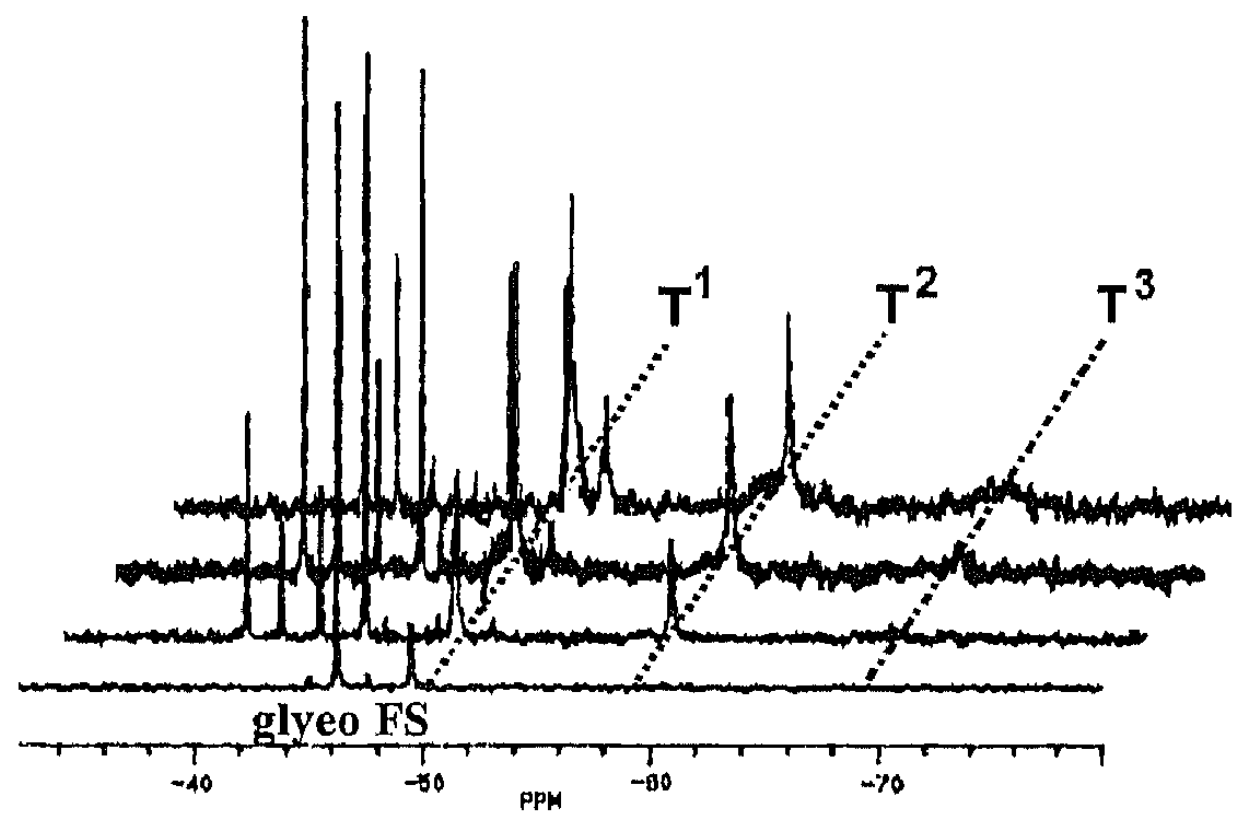

Fig. 12: ${ }^{29} \mathrm{Si-NMR-spectroscopic} \mathrm{investigation} \mathrm{of} \mathrm{the} \mathrm{cohydrolysis} \mathrm{of} \mathrm{glyeo} \mathrm{with} 2.5$ mole- $\%$ of tridecafluoro-1,1,2,2,-tetrahydrooctyl-1-triethoxysilane (FS). The mixture was cohydrolyzed with the stoichiometric amount of 0.1 normal $\mathrm{HCl}$ for $0,2,4$ and 10 hours. The chemical shift of the precursors is $-46 \mathrm{ppm}$ (glyeo) and $-49 \mathrm{ppm}$ (FS).

Due to the fact that "free" perfluorinated side chains are not compatible with an aqueous system, the formation of micell type of structures has to be taken into consideration here, too. It is not clear so far, however, which structure is formed by the suggested micells.

\section{COATING FABRICATION}

Based on results of the synthesis methods, coatings have been prepared on various substrates. Most of the experiments have been carried out with the glyeo/ $/ \mathrm{SiO}_{2}$ /diamo system. As shown in the experimental part, polycarbonate substrates have been coated after a corona treatment. The substrates were dried at room temperature for $30 \mathrm{~min}$ and cured at $130^{\circ} \mathrm{C}$ for four hours. The abrasion resistance was tested with a taber abrader test using aluminum oxide-filled rubber wheels (CS10F) with 1,000 cycles (the standard tests for plastic surfaces is 100 cycles). The load was $500 \mathrm{~g}$. Depending on the coating thickness, the haze was $4 \%$ with $6 \mu \mathrm{m}$ up to $2 \%$ with $9 \mu \mathrm{m}$ coating thickness, which is an extraordinarily high value for optical coatings. During the curing the epoxy ring is reacted to polymer chains.

In fig. 13 the ${ }^{13} \mathrm{C}-\mathrm{MAS}-\mathrm{NMR}$ spectra (solid state) is shown, where the epoxy ring completely has disappeared. 


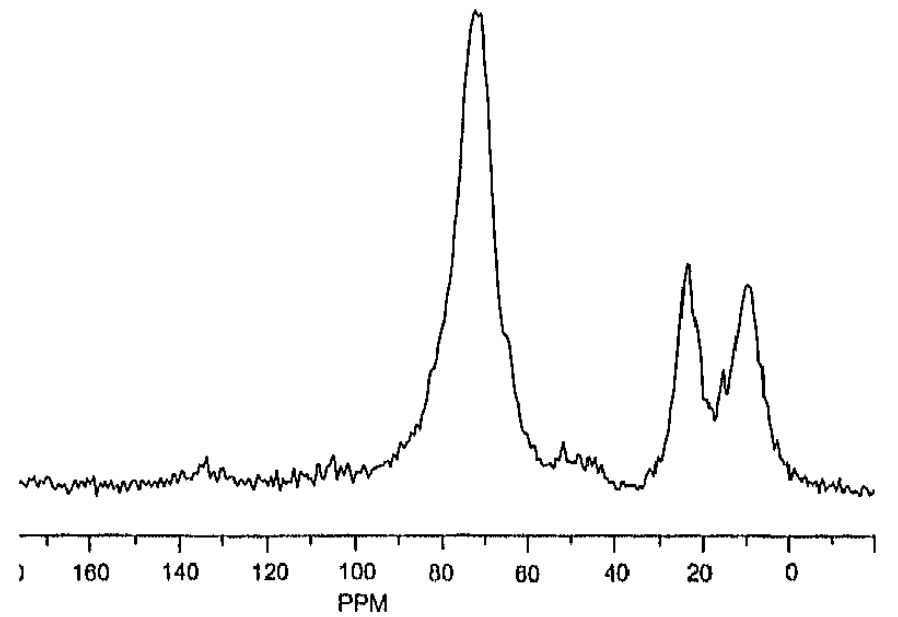

Fig. 13: ${ }^{13} \mathrm{C}-\mathrm{MAS}-\mathrm{NMR}$ spectra (solid state) of the coating system glyeo/ $/ \mathrm{SiO}_{2} /$ diamo, coated by a spin on process on $\mathrm{PC}$ and cured for 2 hrs at $\mathrm{T}=130^{\circ} \mathrm{C}$.

The epoxy ring which shows intensive peaks at about 40 and $50 \mathrm{ppm}$ has disappeared almost completely while forming polyethylenglycol chains $(60-80 \mathrm{ppm})$.

Adhesion tests were performed by the cross cut test followed by the tape test. In both tests the best results (CC/TT 5/5) were obtained. First weathering tests were carried out with a $100 \%$ relative humidity at $40^{\circ} \mathrm{C}$, and within the testing period of 200 hrs no changes in the mechanical and adhesion properties of the layers were obtained. In fig. 14 a polycarbonate substrate partially coated after the taber abrader test is shown. It clearly shows the bigh protection level of this coating.

According to this procedure, an aluminum substrate was coated and also cured at $130^{\circ} \mathrm{C}$. In fig. 15, the result of a corrosion test on a partially coated Al substrate after 700 hrs of salt spraying is shown. The coated part is completely unaffected. The FS containing coatings also have been used for coating of aluminum substrates, and they show contact angles around $90^{\circ}$. Salt spray tests carried out up to 700 hrs up to now did not show any traces of corrosion.

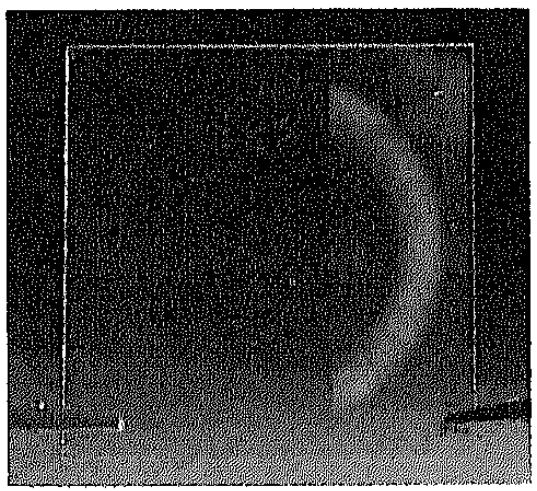

Fig. 14: $\quad$ Half side coated polycarbonate plate (coating material glyeo/ $\mathrm{SiO}_{2} /$ diamo, dipcoated, cured at $130^{\circ} \mathrm{C}$ ) after 1000 cycles taber abrader test $(500 \mathrm{~g}$ load, CS $10 \mathrm{~F}$ roles).

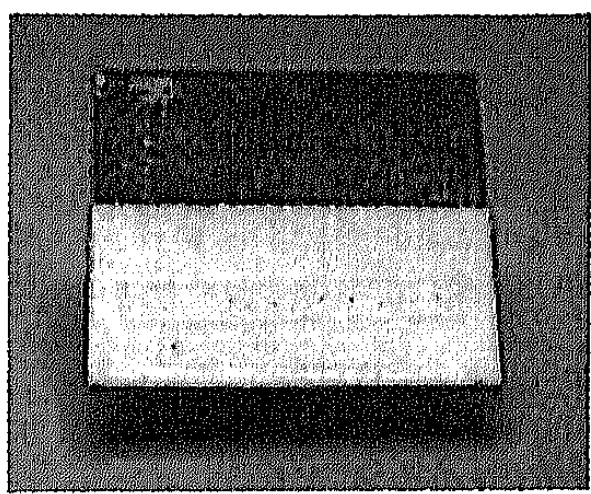

Fig. 15: $\quad$ Half side coated aluminum plate (coating material glyeo/SiO$/ 2$ diamo, dipcoated, cured at $130^{\circ} \mathrm{C}$ ) after 700 hrs salt spray test

\section{CONCLUSION}

The presented investigations have shown that it is possible to process inorganic-organic hybrid materials including nanoparticulate sols to homogeneous materials with extremely low alcohol contents (below $5 \%$ by volume). This opens up an interesting new processing route for hybrid sol-gel materials and may help to overcome one of the important drawbacks of these techniques 
for industrial applications. This first work has shown that using the nanoparticulate approach to produce the so-called nanomers (nanoparticle-modified polymer matrix composites) may be a generalizable route for the fabrication of these materials by avoiding alcoholic or other organic solvents almost completely. Another advantage for industrial application is their high solid content (above $50 \%$ ) while still showing rather low viscosities suitable for various types of coating application like spin coating, spray coating, dip coating, flow coating and others. Despite their water-borne processing route, the water stability of these coating materials is as high as their alcohol-based sister systems. First investigations with other particles like zirconia, titania or alumina have shown that this route can be used to incorporate many types of inorganic nanoparticles and to form transparent coatings.

The authors want to thank the Minister for Research and Culture of the State of Saarland and the Federal Minister for Education, Research and Technology for their financial support (contract number 03M2113B).

1. J. Zarzycki, Past and Present of Sol-Gel Science and Technology. In: J. Sol-Gel Sci. 8, p. 17 - 22 (1997).

2. Better Ceramics Through Chemistry VII: Organic-inorganic hybrid materials, edited by G. L. Wilkes, B. K. Coltrain, C. Sanchez and D. W. Schäfer, (Mater. Res. Soc. Proc. 435, Pittsburgh, PA 1996).

3. H. Schmidt, B. Seiferling, G. Philipp and K. Deichmann in Ultrastructure Processing of Advanced Ceramics, edited by J. D. Mackenzie and D. Ulrich (John Wiley \& Sons, New York, 1998), p. 651-660.

4. R. Kasemann, E. Geiter, H. Schmidt, E. Arpac, G. Wagner and V. Gerhard, 10.11.1993, German Offen DE 4338361 A1.

5. E. Geiter, Ph. D. Thesis, University of Saarland, Saarbruecken, Germany, 1997.

6. R. Kasemann, H. Schmidt and E. Wintrich, Mat. Res. Soc. Symp. Proc. 346, p. $915-921$ (1994).

7. G. Jonschker, in: Proc. Silicones in Coatings II, March 24 - 26, 1998, Lake Buena Vista, Florida/USA (in print).

8. B. G. Bagley, W. E. Quinn, S. A. Khan, P. Barboux, M.-M. Tarascon, J. Non-Cryst. Solids 121, p. 454 (1990).

9. D. E. Valette and D. Yarwood, US patent 5223030 930629; application date: Dec. 02, 1991; publication date: June 29, 1993

10. M. Mennig, G. Jonschker and H. Schmidt, European Patent No. EP 0642475 B1, 06-1996.

11. G. Jonschker, Ph. D. Thesis, University of Saarland, Saarbruecken, Germany, in print.

12. T. Yamamoto; Y. Hori, Nippon Shokubai Co. Ltd.; JP 08060098

13. E. Takeuchi, JP 05306339

14. T. Shimomura; Y. Tbaraki; M. Yokoyama, Dainippon Ink \& Chem. Inc.; JP 63037168

15. R. B. Frye; US 4299746

16. D. Ganbarg; J.M. Schaefer, Tru Vue Inc., WO 9304131

17. S. Kuryama; T. Kawazu; K. Murata, Sanyo Chemical Ind. Ltd., JP 06240203

18. L. Chu, M.W. Daniels, L.F. Francis, Mat. Res. Soc. Symp. Proc. 435, p. 215-225 (1996).

19. H. Schmidt, KONA Powder and Particle, No. 14, (1996) 92 - 103.

20. G. Wagner, Ph. D. Thesis, University of Saarland, Saarbruecken, Germany, 1997.

21. H. Schirra, Master's Thesis, University of Saarland, Saarbruecken, Germany, 1994.

22. H. Schmidt et al., to be published later.

23. P. Krämer, Master's Thesis, University of Saatland, Saarbruecken, Germany, 1997. 